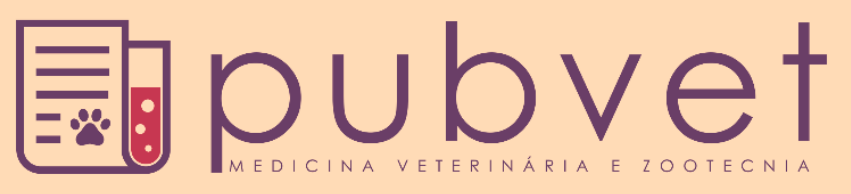

https://doi.org/10.31533/pubvet.v14n9a643.1-6

\title{
Perfil de sensibilidade e casuística do Streptococcus dysgalactiae em mastites na região Noroeste do Estado do RS
}

\author{
Bruna Carolina Ulsenheimer $^{1^{*} \bullet}$, Gabriela Mignoni Amarante ${ }^{2} \bullet$, Silvana Konageski Dalla \\ Rosa $^{3}{ }^{\bullet}$, Simoní Janaina Ziegler ${ }^{4}{ }^{\bullet}$, Camila Naiara Piccinini ${ }^{4}$, Cristiane Beck ${ }^{5} \bullet$, Luciana Mori \\ Viero $^{50}$, Luciane Ribeiro Viana Martins ${ }^{60}$ \\ ${ }^{1}$ Mestranda do Programa de Pós-Graduação em Medicina Veterinária, Universidade Federal de Santa Maria (UFSM). Santa Maria, RS, Brasil. \\ ${ }^{2}$ Acadêmica do curso de Medicina Veterinária da UNIJUÍ, Departamento de Estudos Agrários, Íjuí-RS, Brasil. \\ ${ }^{3}$ Funcionária do Laboratório de Microbiologia Veterinária da UNIJUÍ, Departamento de Estudos Agrários, Íjuí-RS, Brasil. \\ ${ }^{4}$ Médica veterinária, graduada pela UNIJUÍ, Departamento de Estudos Agrários, Íjuí-RS, Brasil. \\ ${ }^{5}$ Professora Doutora do curso de Medicina Veterinária, da UNIJUÍ, Departamento de Estudos Agrários. Íjuí-RS, Brasil. \\ ${ }^{6}$ Professora Mestre do curso de Medicina Veterinária, da UNIJUÍ, Departamento de Estudos Agrários. Íjuí-RS, Brasil. \\ *Autor para correspondência, E-mail: bru.brunna@hotmail.com
}

Resumo. A bactéria Streptococcus dysgalactiae faz parte do grupo dos estreptococos, classificados como cocos Gram-postivo. Encontrada principalmente na cavidade bucal, genitália e na pele da glândula mamária dos animais e no seu ambiente de permanência, é classificada como um patógeno ambiental, que se caracteriza como invasor oportunista do úbere. A mastite causada por esse agente, geralmente se apresenta na forma clínica da doença, com infecções de caráter agudo e grave. Objetivou-se neste trabalho, identificar o agente bacteriano causador de mastites bovina na região Noroeste do Estado do Rio Grande do Sul, isolar o Streptococcus dysgalactiae e determinar seu perfil de sensibilidade frente aos principais antimicrobianos utilizados nesta região para o tratamento da mastite bovina. Foram recebidos para exame de cultura e antibiograma 917 amostras de leite mastítico no Laboratório de Microbiologia Veterinária da Unijuí, durante o período de janeiro de 2012 á maio de 2018. O Streptococcus dysgalactiae, responsável por causar mastite ambiental, principalmente de caráter agudo, foi isolado em 9 casos de mastites, apresentando um perfil de sensibilidade, com alta eficiência antimicrobiana (100\% de sensibilidade) para a ciprofloxacina, cefalotina, enrofloxacina, gentamicina, norfloxacina e sulfazotrim. Desta forma, conclui-se que a prevalência de mastite bovina causada por agentes ambientais dentre eles o $S$. dysgalactiae na região Noroeste do Estado do Rio Grande do Sul é alta.

Palavras chave: antibióticos, bactéria, leite, mastite ambiental

\section{Sensitivity and casuistry profile of Streptococcus dysgalactiae in mastitis in the Northwest region of the State of RS}

\footnotetext{
Abstract. The bacterium Streptococcus dysgalactiae is part of the group of streptococci, classified as Gram-positive cocci. Found mainly in the oral cavity, genitalia and in the skin of the mammary gland of animals and in its permanent environment, it is classified as an environmental pathogen, which is characterized as an opportunistic invader of the udder. Mastitis caused by this agent, usually presents in the clinical form of the disease, with infections of acute and severe character. The objective of this work was to identify the bacterial agent that causes bovine mastitis in the Northwest region of the State of Rio Grande do Sul, to isolate Streptococcus dysgalactiae and to determine its sensitivity profile against the main antimicrobials used in this region for the treatment of bovine mastitis. 917 mastitic milk samples were received for culture and antibiogram examination at the Veterinary Microbiology Laboratory of Unijuí, from January 2012 to May 2018.
} 
Streptococcus dysgalactiae, responsible for causing environmental mastitis, mainly of an acute nature, was isolated in 9 cases of mastitis, presenting a sensitivity profile, with high antimicrobial efficiency (100\% sensitivity) for ciprofloxacin, cephalothin, enrofloxacin, gentamicin, norfloxacin and sulfazotrim. Thus, it is concluded that the prevalence of bovine mastitis caused by environmental agents, among them $S$. dysgalactiae in the Northwest region of the State of Rio Grande do Sul is high.

Keywords: antibiotics, bacteria, milk, environmental mastitis

\title{
Perfil de sensibilidad y casuística de Streptococcus dysgalactiae en mastitis en la región noroeste del estado de RS
}

\begin{abstract}
Resumen. La bacteria Streptococcus dysgalactiae hace parte del grupo de estreptococos, clasificados como cocos grampositivos. Se encuentra principalmente en la cavidad oral, los genitales y en la piel de la glándula mamaria de los animales y en su entorno permanente, se clasifica como un patógeno ambiental, que se caracteriza por ser un invasor oportunista de la ubre. La mastitis causada por este agente, generalmente se presenta en la forma clínica de la enfermedad, con infecciones agudas y graves. El objetivo de este trabajo fue identificar el agente bacteriano que causa la mastitis bovina en la región noroeste del estado de Rio Grande do Sul, aislar Streptococcus dysgalactiae y determinar su perfil de sensibilidad contra los principales antimicrobianos utilizados en esta región para el tratamiento de la mastitis bovina. Se recibieron 917 muestras de leche mastitica para cultivo y examen de antibiograma en el Laboratorio de Microbiología Veterinaria de Unijuí, de enero de 2012 a mayo de 2018. Streptococcus dysgalactiae, responsable de causar mastitis ambiental, principalmente de naturaleza aguda se aisló en 9 casos de mastitis, presentando un perfil de sensibilidad, con alta eficacia antimicrobiana (100\% de sensibilidad) para ciprofloxacina, cefalotina, enrofloxacina, gentamicina, norfloxacina y sulfazotrim. Por lo tanto, se concluye que la prevalencia de mastitis bovina causada por agentes ambientales, entre ellos $S$. dysgalactiae en la región noroeste del estado de Rio Grande do Sul, es alta.
\end{abstract}

Palabras clave: antibióticos, bacterias, leche, mastitis ambiental

\section{Introdução}

Doenças infecciosas causadas por agentes bacterianos são cada vez mais frequentes ao redor do mundo (Araújo et al., 2004). Dentre as doenças infecciosas mais significativas, se encontra a mastite bovina, constantemente presente na atividade leiteira (E. O. Costa et al., 1995). A qual se caracteriza, por um processo inflamatório da glândula mamária, causado geralmente por bactérias (Tozzetti et al., $\underline{2008}$ ). Com relação as bactérias causadores das mastites, encontram-se os patógenos ambientais que são descritos como invasores oportunistas do úbere, como a Escherichia coli, Streptococcus uberis e Streptococcus dysgalactiae (Quinn et al., 2005; Tozzetti et al., 2008).

A bactéria Streptococcus dysgalactiae faz parte do grupo dos estreptococos, classificados como cocos Gram-postivo (Bibersrtin \& Hirsh, 2009; Gasparotto et al., 2016; Quinn et al., 2005). Encontrada na cavidade bucal, genitália e na pele da glândula mamária dos animais, bem como no seu ambiente de permanência (Quinn et al., 2005; Stewart, 2017).

A mastite causada por Streptococcus dysgalactiae, geralmente se apresenta na forma clínica da doença, com infecções de caráter agudo e grave (Bibersrtin \& Hirsh, 2009; Stewart, 2017). Com maior concentração no período pós-parto e estação chuvosa (Taffarel et al., 2015), causando aumento das células somáticas que pode ocorrer em todo o período lactente (Costa et al., 2017). Esta enfermidade se caracteriza por ocasionar grandes prejuízos, que se estendem desde os produtores rurais, até as indústrias que utilizam o leite como matéria-prima e principalmente os consumidores, que podem sofrer com consequências à saúde decorrentes da ingestão de leite contendo microrganismos patogênicos (Bandoch \& Melo, 2011).

Os objetivos deste trabalho são identificar o agente bacteriano causador da mastite bovina em amostras de leite provenientes da região Noroeste do Rio Grande do Sul, bem como isolar o 
Streptococcus dysgalactiae e determinar o seu perfil de sensibilidade frente aos principais antimicrobianos utilizados nesta região para o tratamento da mastite bovina.

\section{Material e métodos}

O trabalho foi desenvolvido no Laboratório de Microbiologia Veterinária da UNIJUÍ, a partir das amostras de leite encaminhadas por produtores e Médicos Veterinários da região Noroeste do Estado do Rio Grande do Sul, no período de janeiro de 2012 a maio de 2018, totalizando 917 amostras de leite analisadas até o momento. Foi realizado cultivo, identificação bacteriana e análise do perfil de sensibilidade antimicrobiana de antibióticos, comumente utilizados na rotina laboratorial, ampicilina $(10 \mu \mathrm{g})$, ciprofloxacina $(5 \mu \mathrm{g})$, cefalexina $(30 \mu \mathrm{g})$, cefalotina $(30 \mu \mathrm{g})$, eritromicina $(15 \mu \mathrm{g})$, enrofloxacina $(5 \mu \mathrm{g})$, gentamicina $(10 \mu \mathrm{g})$, norfloxacina $(10 \mu \mathrm{g})$, penicilina (10 UI), sulfazotrim $(25 \mu \mathrm{g})$ e tetraciclina $(30 \mu \mathrm{g})$.

Cada amostra foi identificada, e posteriormente semeada em meio específico, ágar sangue ovino 5\% e ágar McConkey e incubadas a $36^{\circ} \mathrm{C}$ em estufa bacteriológica por um período de 48 horas. Após este período, fez-se a observação visual das colônias crescidas nos meios de cultura e a partir daí realizouse a confecção de esfregaços em lâminas e coloração de Gram, para a primeira identificação morfotintorial. Posteriormente, a lâmina foi examinada em microscópio óptico, onde observou-se as características morfológicas do microrganismo encontrado, então, as amostras foram transferidas para meios contendo substâncias que evidenciam o metabolismo e a presença de enzimas, possibilitando assim a identificação bacteriana, presente na amostra de leite.

Após este processo de identificação, foi realizado o perfil de sensibilidade antimicrobiana, onde alíquotas da amostra bacteriana isolada de Streptococcus dysgalactiae foram passadas para placas com ágar Mueller Hinton, e espalhadas por toda sua superfície. Após, foram colocados os discos de antibióticos sobre o ágar semeado, então foram mantidas em estufa bacteriológica a $36^{\circ} \mathrm{C}$ por 24 horas.

Posteriormente foram feitas análises e medidas do tamanho dos halos de sensibilidade aos antibióticos, classificando-o em sensível, quando foi efetivo no combate a bactéria, intermediário, quando possui ação parcial no combate aos microrganismos, e resistente, se for um medicamento que não consiga agir sobre a bactéria causadora da mastite.

\section{Resultados e discussão}

Neste trabalho, foram identificadas 30 diferentes espécies bacterianas causadoras de mastite na região da grande bacia leiteira, no Noroeste do Estado do Rio Grande do Sul. Na região do município de Carlinda, Mato Grosso, Silva et al. (2017) observaram prevalência de mastites bacterianas em 87,5\% do rebanho leiteiro. Segundo Santos \& Fonseca (2001), a disseminação de bactérias ambientais, ocorre principalmente no período seco, devido à presença das bactérias no solo, fezes, lama e camas orgânicas. Em casos de infecções intra-mamárias causadas por $S$. dysgalactiae, a vaca apresentará mastite geralmente com caráter clínico logo após o parto ( $\underline{\text { Santos \& Fonseca, 2001)}}$.

Ao diagnóstico de mastites bovinas causadas por Streptococcus dysgalactiae, no exame microbiológico esta bactéria produziu colônias claras com diâmetro menor que $1 \mathrm{~mm}$, indo de encontro ao descrito por Stewart (2017).

Conforme as análises, a maioria dos agentes isolados no Laboratório de Microbiologia Veterinária da Unijuí, são ambientais, dentre eles se encontra o Streptococcus dysgalactiae. Este microrganismo foi o agente etiológico presente em 09 das amostras de leite analisadas, conforme apresentado no gráfico 1.

Dos agentes causadores das mastites ambientais, o Streptococcus uberis foi o mais isolado, seguido da Escherichia coli, e em seguida o Streptococcus dysgalactiae.

Em estudo realizado por Ulsenheimer et al. (2018) na região do Noroeste do Estado do Rio Grande do Sul, o Streptococcus dysgalactiae, foi isolado em 1,30\% do total de 702 análises. Já neste trabalho observa-se que houve um decréscimo na porcentagem de mastites causadas por esse agente nessa mesma região, diminuindo para 1\% do total de 917 análises. Em contraponto com o presente estudo, Martins et al. (2010) observaram que na microrregião de Cuiabá, a mastite bovina causada por Streptococcus ambientais foi de baixa prevalência. Segundo Quinn et al. (2005), os Streptococcus dysgalactiae estão envolvidos com lesão nos tetos, sendo comumente associado à mastite no período seco. 
Com relação ao perfil de sensibilidade apresentado pelo Streptococcus dysgalactiae em relação ao antimicrobianos comumente utilizados na rotina do laboratório de Microbiologia Veterinária da Unijuí, estão demonstrados na tabela 1.

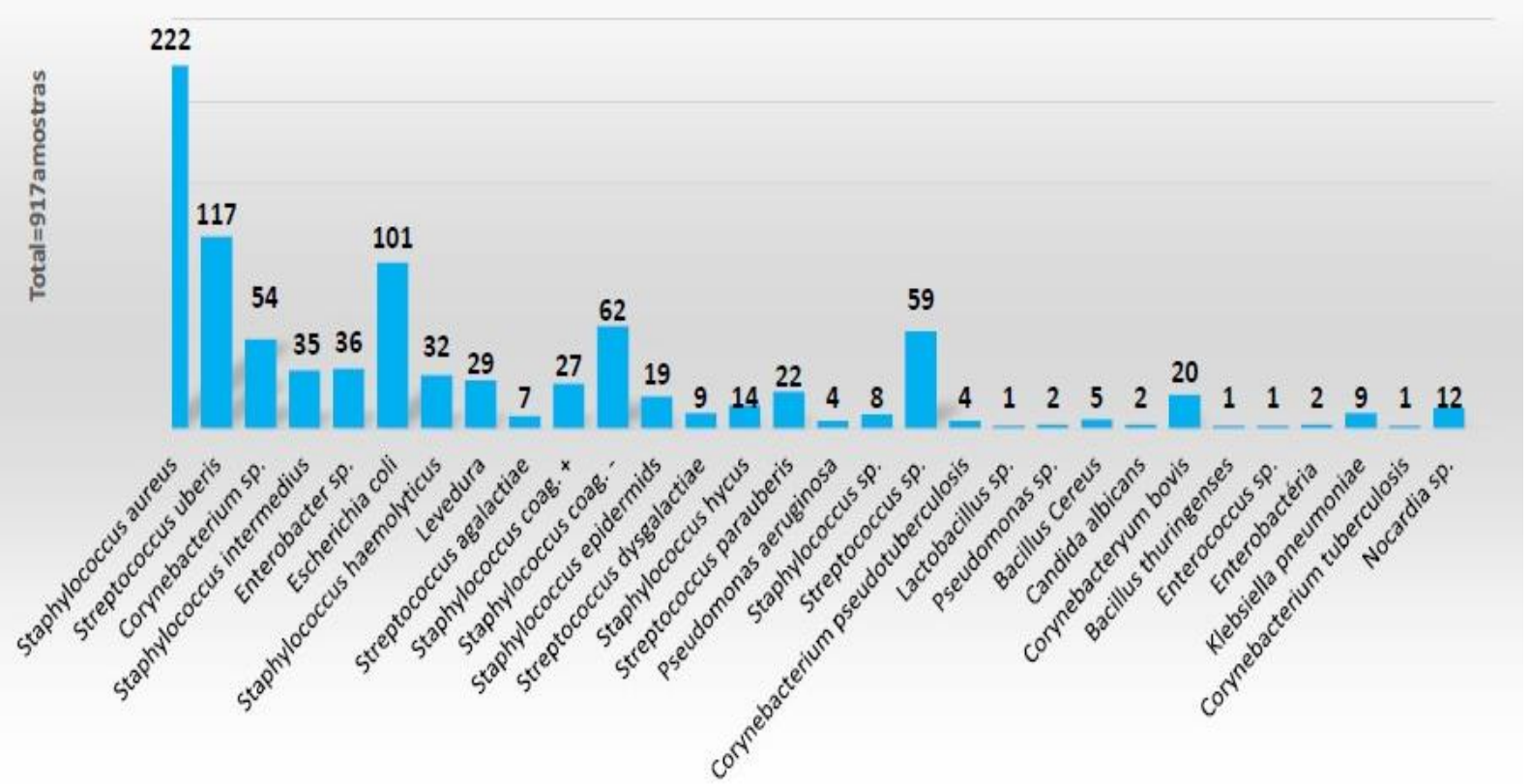

Gráfico 1. Microrganismos isolados em análises de leite mastítico da região Noroeste do Estado do Rio grande do Sul. LAMIVET, UNIJUI, 2018

Tabela 1. Percentual de sensibilidade dos antimicrobianos frente cepas de S. dysgalactiae

\begin{tabular}{lccccccccccc}
\hline $\begin{array}{l}\text { Agente } \\
\text { etiológico }\end{array}$ & $\mathrm{AMP}^{1}$ & $\mathrm{CIP}^{2}$ & $\mathrm{CFX}^{3}$ & $\mathrm{CFL}^{4}$ & $\mathrm{ENO}^{5}$ & $\mathrm{ERI}^{6}$ & $\mathrm{GEN}^{7}$ & $\mathrm{NOR}^{8}$ & $\mathrm{PEN}^{9}$ & $\mathrm{SUT}^{10}$ & TET $^{11}$ \\
\hline $\begin{array}{l}\text { Streptococcus } \\
\text { dysgalactiae, } \%\end{array}$ & 63 & 100 & 83 & 100 & 100 & 63 & 100 & 100 & 63 & 100 & 63 \\
\hline
\end{tabular}

${ }^{1}$ Ampicillina. ${ }^{2}$ Ciprofloxacina, ${ }^{3}$ Cefalexina, ${ }^{4}$ Cefalotina, ${ }^{5}$ Enrofloxacina, ${ }^{6}$ Eritromicina, ${ }^{7}$ Gentamicina, ${ }^{8}$ Norfloxacina, ${ }^{9}$ Penicilina, ${ }^{10}$ Sulfazotrin, ${ }^{11}$ Tetraciclina

O perfil de sensibilidade do Streptococcus dysgalactiae observado neste estudo, indica antibióticos que ainda possuem alta eficiência antimicrobiana relacionada às cepas da região. Sendo que a Ciprofloxacina, Cefalotina, Enrofloxacina, Gentamicina, Norfloxacina e Sulfazotrim apresentaram grande eficiência antimicrobiana ás cepas bacterianas em 100\% das análises realizadas.

Já Souza et al. (2016) encontraram alta eficiência antimicrobiana da gentamicina, seguido de amicacina e cefalexina paras as cepas bacterianas do gênero Staphylococcus e Streptococcus isoladas na região de Bocaiúva - MG. Demonstrando que a gentamicina é um dos antibióticos mais eficientes nas duas regiões.

Os antibióticos com menor eficiência antimicrobiana foram a Ampicilina, Eritromicina, Penicilina, Tetraciclina e Cefalexina. Segundo Ulsenheimer et al. (2018) também foram os antimicrobianos com menor eficiência em seu estudo com microrganismos causadores de mastite. Sendo encontrado altos valores de resistência à penicilina também por Souza et al. (2016).

Para a produção de leite de qualidade, é essencial o controle da mastite bovina (Pedrini \& Margatho, 2003). E para o controle de mastites causada por S. dysgalactiae, Santos \& Fonseca (2001) sugerem redução da exposição das extremidades dos tetos aos patógenos do ambiente e um aumento da imunidade do animal.

Para estagnar o desenvolvimento de microrganismos resistentes aos antibióticos, além de realizar o antibiograma, é necessário cautela ao utilizar os antimicrobianos em práticas terapêuticas no tratamento de doenças infecciosas em animais, como para o caso das mastites (Costa et al., 2013; Ribeiro et al., 2012). 


\section{Conclusão}

Desta forma, conclui-se que a prevalência de mastite bovina causada por agentes ambientais na região Noroeste do Estado do Rio Grande do Sul é alta, sendo o Streptococcus dysgalactiae, um dos microrganismos encontrado.

\section{Referências bibliográficas}

Araújo, J. C. L. V, Lima, E. O., Ceballos, B. S. O., Kristerson, R. L., Souza, E. L., \& Santos Filho, L. (2004). Ação antimicrobiana de óleos essenciais sobre microrganismos potencialmente causadores de infecções oportunistas. Revista de Patologia Tropical/Journal of Tropical Pathology, 33(1), 5564. DOI: https://doi.org/10.5216/rpt.v33i1.3189

Bandoch, P., \& Melo, L. (2011). Prevalência de mastite bovina por Staphylococcus aureus: uma revisão bibliográfica. Publicações UEPG Biologicas, Sciences, 17(1), 47-51. DOI: https://doi.org/10.5212/Publ.Biologicas.v.17i1.0005

Bibersrtin, E. L., \& Hirsh, D. C. (2009). Estreptococos. In D. C. Hirsh \& Y. Zee (Eds.), Microbiologia Veterinária (pp. 113-116). Koogan Guanabara.

Costa, E. O., Carciofi, A. C., Benites, N. R., Melville, P. A., Pardo, R. B., Ribeiro, A. R., \& Watanabe, E. T. (1995). Estudo etiológico da mastite clínica bovina. Revista Brasileira de Medicina Veterinária, 17(4), 156-158.

Costa, G. M., Barros, R. A., Costa Custódio, D. A., Pádua Pereira, U., Figueiredo, D. J., \& Silva, N. (2013). Resistência a antimicrobianos em Staphylococcus aureus isolados de mastite em bovinos leiteiros de Minas Gerais, Brasil. Arquivos Do Instituto Biológico, 80(3), 297-302. DOI: https://doi.org/10.1590/s1808-16572013000300006

Costa, H. N., Molina, L. R., Lage, C. F. A., Malacco, V. M. R., Facury Filho, E. J., \& Carvalho, A. Ú. (2017). Estimativa das perdas de produção leiteira em vacas mestiças Holandês x Zebu com mastite subclínica baseada em duas metodologias de análise. Arquivo Brasileiro de Medicina Veterinária e Zootecnia, 69(3), 579-586. DOI: https://doi.org/10.1590/1678-4162-9019

Gasparotto, P. H., Weber, F. K., Barbosa, V. A. A., de Moraes, L. B., Bicalhos, B., \& Sobral, F. O. S. (2016). Principais gêneros bacterianos causadores de matite isolados no Laboratório de Microbiologia Veterinária do Hospital veterinário do Centro Universitário Luterano de JiParaná/RO. Revista Veterinária Em Foco, 14(1), 60-70.

Martins, R. P., Silva, J. A. G., Nakazato, L., Dutra, V., \& Almeida Filho, E. S. (2010). Prevalência e etiologia infecciosa da mastite bovina na microrregião de Cuiabá-MT. Ciência Animal Brasileira, 11(1), 181-187. DOI: https://doi.org/10.5216/cab.v11i1.5085

Pedrini, S. C. B., \& Margatho, L. F. F. (2003). Sensibilidade de microrganismos patogênicos isolados de casos de mastite clínica em bovinos frente a diferentes tipos de desinfetantes. Arquivo Do Instituto Biológico de São Paulo, 70(4), 391-395.

Quinn, P. J., Markey, B. K., Carter, M. E., Donnelly, W. J., \& Leonard, F. C. (2005). Microbiologia veterinária e doenças infecciosas. Artmed.

Ribeiro, D. S., Melo, D. B., Guimarães, A. G., \& Velozo, E. S. (2012). Avaliação do óleo essencial de alecrim (Rosmarinus officinalis L.) como modulador da resistência bacteriana. Semina: Ciências Agrárias, 33(2), 687-695. DOI: https://doi.org/10.5433/1679-0359.2012v33n2p687

Santos, M. V, \& Fonseca, L. F. L. (2001). Importância e efeito de bactérias psicrotróficas sobre a qualidade do leite. Higiene Alimentar, 13-19.

Silva, A. C., Silva, F. F., \& Bett, V. (2017). A prevalência de mastites em vacas leiteiras do município de Carlinda (MT), no ano de 2016. PUBVET, 11(8), 761-766. DOI: https://doi.org/10.22256/pubvet.v11n8.761-766

Souza, K. S. S., Oliveira, Y. C. M., Duarte, A. F. V., Oliveira, T. C., Veloso, Á. L. C., Oliveira, P. M. C., \& Fernandes, N. S. F. (2016). Avaliação da sensibilidade dos agentes etiológicos causadores da mastite subclínica a antimicrobianos em vacas leiteiras. Caderno De Ciências Agrárias, 8(2), 83-89.

Stewart, G. C. (2017). Streptococcus e enterococcus. In D. S. McVey, M. Kennedy, \& M. M. Chengappa (Eds.), Microbiologia Veterinária (pp. 199-200). Koogan Guanabara. 
Taffarel, L. E., Costa, P. B., Tsutsumi, C. Y., Klosowski, E. S., Portugal, E. F., \& Lins, A. C. (2015). Variação da composição e qualidade do leite em função do volume de produção, período do ano e sistemas de ordenha e de resfriamento. Semina: Ciências Agrárias, 36(3-Supl-1), 2287-2300. DOI: https://doi.org/10.5433/1679-0359.2015v36n3supl1p2287

Tozzetti, D. S., Bataier, M. B. N., Almeida, L. R., \& Piccinin, A. (2008). Prevenção, controle e tratamento das mastites bovinas-revisão de literatura. Revista Científica Eletrônica de Medicina Veterinária, 6(10), 1-7.

Ulsenheimer, B. C., Amarante, G. M., Silva, L. S., \& Martins, L. R. V. (2018). Mastites causadas por streptococcus hycus sua ocorrência e perfil de sensibilidade na região noroeste do estado do Rio Grande do Sul. Brazilian Journal of Animal and Environmental Research, 1(2), 329-337.

Recebido: 29 de abril, 2020

Aprovado: 5 de junho, 2020

Disponível online: 17 de agosto, 2020

Licenciamento: Este artigo é publicado na modalidade Acesso Aberto sob a licença Creative Commons Atribuição 4.0 (CC-BY 4.0), a qual permite uso irrestrito, distribuição, reprodução em qualquer meio, desde que o autor e a fonte sejam devidamente creditados. 